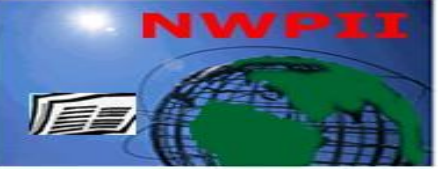

American Journal of Biomedical Sciences

ISSN: 1937-9080

nwpii.com/ajbms

\title{
Latent Natural Product and Their Potential Application as Anti-Infective Agents
}

\author{
Fatima Syed ${ }^{1}$, Raheela Taj ${ }^{1}$, Nusrat Shaheen $^{3}$, Musarat Norin ${ }^{1}$ and Shafiullah Khan ${ }^{2,3 *}$ \\ ${ }^{1}$ Institute of Chemical Science, University of Peshawar, KPK, Pakistan \\ ${ }^{2}$ Department of Chemistry, Gomal University, Dera Ismail Khan, KPK, Pakistan \\ ${ }^{3}$ Stat Key Laboratory of Organic-Inorganic Composites, Beijing University of Chemical Technology, Beijing, China \\ *Corresponding Author \\ Prof. Dr. Shafiullah Khan \\ Department of Chemistry \\ Gomal University \\ D.I.Khan, Pakistan \\ Email: s.khan@gu.edu.pk
}

Received: 11 December 2013; | Revised: 5 February 2014; | Accepted: 17 February 2014

\begin{abstract}
Extract of Acorus calamus (AC) and Ferula asafetida (FA), were tested against different bacterial pathogens by well-cut agar diffusion method. To analyzed the in vitro activities of $A$. calamus (AC) and $F$. asafetida (FA) against four different bacteria (Escherichia coli, Staphylococcus epidermidis, Staphylococcus aureus and Bacillus subtilis were used. A. calamus (AC) had a broad spectrum antimicrobial effect against different bacterial pathogens. Streptomycin was used as standard drug with significant activity values i.e., 34 $\mathrm{mm}$ against Staphylococcus aureus, $36 \mathrm{~mm}$ against Staphylococcus epidermidis, $30 \mathrm{~mm}$ against Bacillus subtilis and $24 \mathrm{~mm}$ against Escherichia coli. Analysis of the data showing that, the crude extract of $A$. calamus (AC) in n-hexane exhibited superior activity against Staphylococcus epidermidis. The dichloromethane extract of $F$. asafetida $(F A)$ was found low against Escherichia coli and Bacillus subtilis. Results were compared concomitantly to standard drugs; Streptomycin. Phytochemical screening of $A$. calamus (AC) and $F$. asafetida (FA) showed presence of terpenoids, saponins, flavonoids, alkaloids, tannins, glycosides and reducing sugar components. The high potency of $A$. calamus and $F$. asafetida against these microbes could provide an example of prospecting for new compounds. Based on the current conclusion, it can be accomplished that these plants has antimicrobial activity, which is as potent as standard antimicrobial drugs against specific microorganisms.
\end{abstract}

Keywords: Acorus calamus and Ferula asafetida, Infection, Inhibition, Phytochemical screening, Medicinal plants. 


\section{Introduction}

The phytochemical research, in which ethno pharmacological properties of plants are evaluated, leads to the discovery of new antiinfective agents from higher plants. Owing to the development of drug resistive strains in human pathogens against commonly used antibiotics, it is necessary to discover new antimicrobial substances from plants and other sources. Popular European books on medicinal plants touted calamus as a "wonder drug." It was commonly used in folk medicine as a "nervine," most likely linked to the tranquilizing effect of cis-isoasarone In Exodus 30: 23, 24, 34, it has been written that God ordered Moses to make the Holy Oil, one of its constituents was an aromatic reed which some authorities have suggested might have been Acorus calamus. Some people strung together its dried root pieces, steam it throughout the home, thought to "kill" sickness. Acorus calamus Linn is commonly known as sweet flag is an aromatic medicinal plant belonging to the Araceae family. It has been long known for its medicinal value, it is wild or cultivated throughout Himalayas at an altitude ascending up to $6000 \mathrm{ft}$. The rhizomes of Acorus calamus contain aromatic oil that has been used medicinally since ancient times and has been harvested commercially [11]. The most common way of ingesting Acorus calamus is by chewing it. It can be peeled and washed to remove the bitterness and then eaten raw like a fruit. The dried and powdered rhizome has a spicy flavor and is used as a substitute for ginger, cinnamon and nutmeg. A pinch of the powdered rhizome is used as a flavoring in tea. The inner portion of young stems makes a very palatable salad. Sweet flag has a very long history of medicinal use in Chinese and Indo-Pak herbal traditions [8].

It is widely employed in modern herbal medicine as its sedative, laxative, diuretic, and carminative properties [10]. It is used in Ayurveda to counter the side effects of all hallucinogens. Both roots and leaves of $A$. calamus have shown strong antioxidant [4]. It is used as antimicrobial against various bacteria, filamentous fungi, and yeast [3]. Acorus calamus is effective against cattle tick, Rhipicephalus (Boophilus) microplus [6]. A recent study showed that beta-asarone isolated from Acorus calamus oil inhibits adipogenesis in 3T3-L1 cells and thus reduces lipid accumulation in fat cells [7]. Protective effect against acrylamide induced neurotoxicity [9]. Chewing the root of calamus helps fight tobacco addiction i.e., it kills the taste for tobacco over time [14]. The plant is externally used to treat skin eruptions, rheumatic pains and neuralgia. It is used in incense sticks and dhup and is widely used as insecticide for lice, bedbugs, worms etc. Sweet Flag is used as an antihistamine [2]. A. calamus uses are, Abortifacient; Anodyne; Aphrodisiac; Aromatic ; Carminative; Diaphoretic; Emmenagogue; $\mathrm{Fe}$ brifuge;Hallucinogenic; Homeopathy; Odontalgi c; Sedative; Stimulant; Stomachic; Tonic; Vermifuge. Ferula is a genus of about 170 species of flowering plants in the family Apiaceae. It is native to the Mediterranean region east to central Asia, mostly growing in arid climates. It is strictly distributed Pakistan, India, Iran, and Afghanistan. Ferula asafetida has a pungent, unpleasant smell when raw, but in cooked dishes, it delivers a smooth flavor, reminiscent of leeks. Plant prefers full sun and dry soil [12].

Ferula asafetida has shown remarkable antioxidant and antihemolytic activities. It reduces the growth of indigenous microflora in the gut, reducing flatulence. It is effective against Swine flu virus. Used for treating chronic bronchitis and whooping cough, as well as reducing flatulence.

Ferula asafetida has also been reported to have contraceptive/abortifacient activity, Ferula asafetida oleo-gum-resin has been reported to be antiepileptic Roots yield an oleo-gum-resin used as an expectorant, antispasmodic and spice inhaling this gum prevents hysterical attacks. Ferula asafetida is useful in alleviating toothache. This spice is used as a digestive aid, in food as a condiment and in pickles [15]. 


\section{Material and Method}

\subsection{General experimental procedure}

Melting point was determined by using Kofler hot-stage apparatus (Reichert, Vienna, Austria). Glass capillaries were used and melting points are uncorrected. Aluminium TLC plates $(20 \times 20,0.5 \mathrm{~mm}$ thick) precoated with silica gel $60 \mathrm{~F}_{254}(20 \times 20 \mathrm{~cm}, 0.2 \mathrm{~mm}$ thick; E.Merck, Darmstadt, Germany) were used for TLC. All chemicals were purchased from Sigma Chemical Company (St Louis, MO, USA). The bacteria used were originally from the American type culture collection (ATCC), USA. They were obtained from School of Life Science and Technology, Beijing University of Chemical Technology, China, where these were identified and characterized. Strains used were Escherichia coli ATCC25922, Staphylococcus epidermidis ATCC12228, Staphylococcus aureus ATCC25923 and Bacillus subtilis NCTC8236. These strains were maintained on agar slants at $4^{\circ} \mathrm{C}$ in School of Life Science and Technology, Beijing University of Chemical Technology for antimicrobial tests. Microorganisms were incubated overnight at $37^{\circ} \mathrm{C}$ in Mueller-Hinton Broth (Oxoid) at pH 7.4.

\subsection{Plant Materials}

Rhizome of Acorus calamus and gum of Ferula asafetida were collected from Malakand, Pakistan. The taxonomic identification of both these plants was carried out by Dr. Farrukh Hussain at the Department of Botany (DOB), University of Peshawar, Pakistan. A voucher specimen under the scientific name of the plant was deposited at the herbarium of DOB.

\subsection{Preparation of crude extract}

Plants materials were dried under shade and powered. From these powered materials, weighed amount was taken in separate thimbles. This was suspended above the flask containing the solvent $\mathrm{n}$-Hexane fitted with reflux condenser. The flask was heated $\left(60-65^{\circ} \mathrm{C}\right.$ for $\left.5-6 \mathrm{hrs}\right)$ on heating mantle the evaporated solvent upon condensation trickled into the extraction chamber containing the plant material. The extraction chamber was designed so that when the solvent surrounding the sample exceed a certain level, it overflowed and trickled back down into the boiling flask. At the end of the extraction process, the flask containing the n-Hexane extract was removed. After the removal of n-Hexane extract the plant material was remain in thimble and next solvent of high polarity was passed like Dichloromethane and extract was obtained and then Ethyl acetate and at the end highly polar solvent Ethanol was passed and thus different extract were obtained according to increasing polarities of solvents. The solvents obtained were evaporated under vacuum using rotary evaporator. The plants extracts were collected in labeled vials. The plant materials taken for extraction were Acorus calamus (70 g) and Ferula asafetida $(65 \mathrm{~g})$. The crude extracts were subjected for anti-bacterial activity and their phytochemical screening.

\subsection{Qualitative analysis of chemical constituents}

Chemical analysis for the presence of major classes of secondary metabolites (alkaloids, tannins, anthraquinones, glycosides, reducing sugars, saponins, flavonoids, phlobatanins, steroids and terpenoids) in the crude extracts was carried out according to the method described by Pearson [13].

\section{Antimicrobial assay}

\subsection{Preparation of medium}

Two of types of media were used, solid medium, Liquid medium. Nutrient agar $16.8 \mathrm{~g}$ was dissolved in distilled water and volume was made up to 0.6 liter. It was autoclaved at $120{ }^{\circ} \mathrm{C}$ for 15 minutes. Media was cooled and allow to solidify in Petri dishes. Nutrient broth $1.9 \mathrm{~g}$ was dissolved in distilled water and volume was made up to $150 \mathrm{ml}$. $8 \mathrm{ml}$ of this broth was added to screw capped test tubes, which were placed in autoclave at $120^{\circ} \mathrm{C}$ for 15 minutes, then refrigerated at $37{ }^{\circ} \mathrm{C}$.

\subsubsection{Preparation of tested materials}

The test sample were Prepared by dissolving $21 \mathrm{mg}$ of crude extract in $1 \mathrm{~mL}$ of DMSO in eppendorff tube and kept for $1 \mathrm{hr}$. To 
another eppendorff tube, $1 \mathrm{mg}$ of streptomycin was dissolved in $1 \mathrm{~mL}$ DMSO and kept for $1 \mathrm{hr}$.

\subsection{Antibacterial assay}

\subsubsection{Cup-plate diffusion method}

Antibacterial activity of plant extracts was carried using cup-plate agar diffusion method [14] with some small modifications. One $\mathrm{ml}$ from each standard bacterial stock suspension was mixed thoroughly with $40-45 \mathrm{ml}$ of sterile Molten Muellur Hinton agar $40^{\circ} \mathrm{C}$, poured into sterile Petri-dishes and left to solidify. Then, four cupshape wells (120 mm diameter) were made in each plate using sterile cork-borer. The agar disks were removed and four alternate cups were filled with extract using sterile adjustable pipettes. Four Petri-dishes with two alternate cups were used with the respective solvent instead of the extracts as control. The plates were then incubated in upright position for 22 to $24 \mathrm{~h}$ at room temperature. Two replicates were carried out for each extract. After incubation period, the inhibition zones diameters were measured.

\subsubsection{Disc diffusion method}

The antibacterial assay for plant extract was also conducted using disc diffusion method as illustrated by Abdel-Wahab et al [1]. The nutrient agar solution (16 mL) was poured and kept overnight in a refrigerator. Whatman filter paper discs of $6 \mathrm{~mm}$ diameter were impregnated with $10 \mu \mathrm{L}$ of the solution of crude extract (at $4 \mathrm{mg}$ ml-1) dissolved in dimethyl sulfoxide (DMSO). Standard disc of streptomycin sulphate $(10 \mu \mathrm{g} / \mathrm{disc})$ was used as positive control, while DMSO was used as a negative control. The Petri dishes were inverted and incubated for $24 \mathrm{~h}$ at $37^{\circ} \mathrm{C}$. Clear inhibition zones around the discs indicated the presence of antimicrobial activity.

Table 1. Secondary metabolites detected in different extracts of Acorus calamus

\begin{tabular}{lcccc} 
Chemical components & n-Hexane & DCM & Ethylacetate & Ethanol \\
\hline & & & & \\
Alkoloids & + & ++ & ++ & +++ \\
Tannins & - & - & ++ & ++ \\
Anthraquinones & - & - & - & - \\
Glycosides & - & - & - & ++ \\
Reducing sugar & - & - & - & ++ \\
Saponins & - & + & - & +++ \\
Flavonoids & - & + & - & + \\
Phlobatanins & - & - & - & - \\
Terpenoids & ++ & +++ & ++ & ++
\end{tabular}

+++ = High concentration; $++=$ Moderate concentration $;+=$ Low concentration, $-=$ Absent 
Table 2. Secondary metabolites detected in different extracts of Ferula assafoetida.

Chemical components n-Hexane DCM Ethylacetate $\quad$ Ethanol

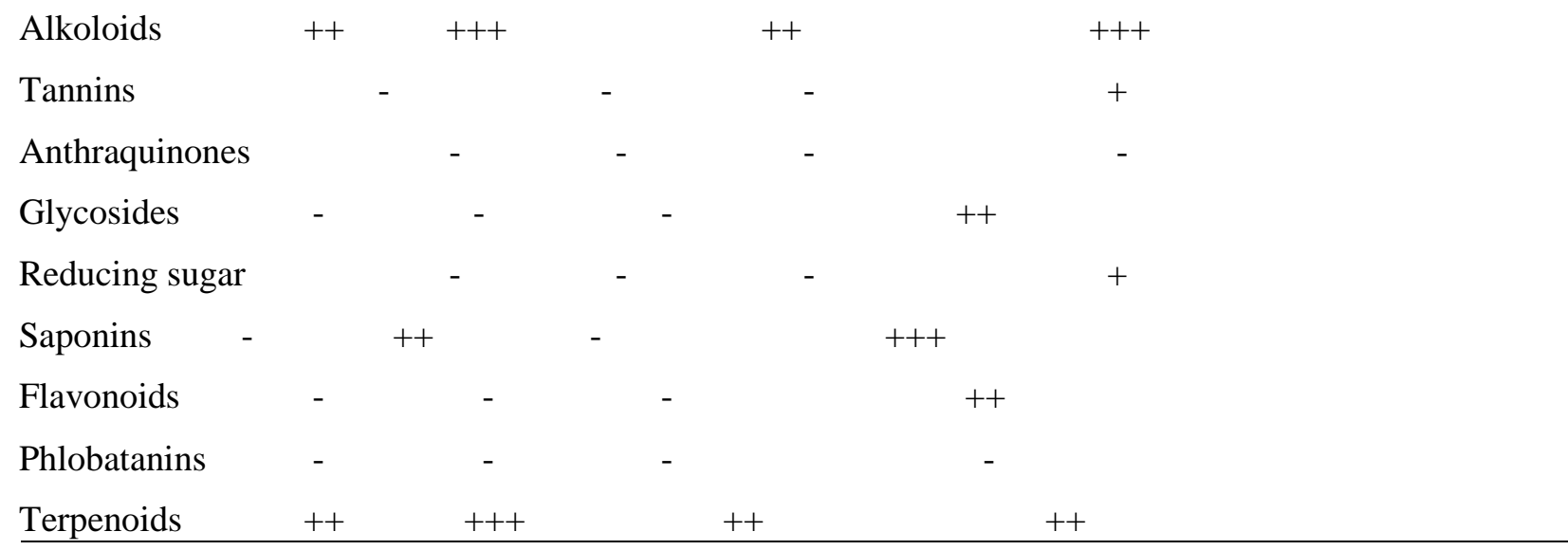

+++ = High concentration; $++=$ Moderate concentration; $+=$ Low concentration, - = absent

\section{Results}

\subsection{Phytochemical screening}

Phytochemical screening of chemical constituents of crude extract in different solvents showed the presence of alkaloids, tannins, anthraquinones, glycosides, reducing sugars, saponins, flavonoids, phlobatanins, steroids and terpenoids constituents in table 1 and 2 according to Syed et al [5].

\subsubsection{Antimicrobial screening}

The results were summarized in Tables 3 . However, results were interpreted in terms of commonly used terms: sensitive, intermediate and resistant. Findings of cup-plate diffusion method for ethanolic extracts of A. calamus and F. asafetida are exposed in figure $1 \& 2$.

Table 3. Antibacterial activity of $A$. calamus and $F$. asafetida.

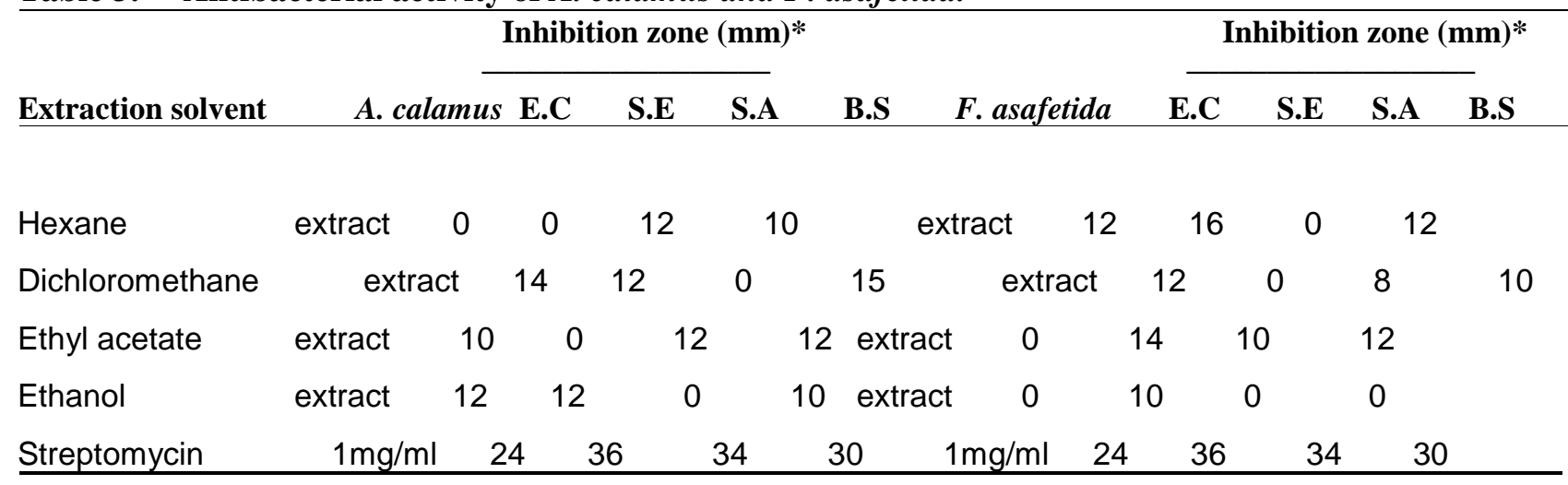

E.C. Escherichia coli, S.E. Staphylococcus epidermidis, S.A. Staphylococcus aureus, B.S. Bacilis subtili: 


\subsubsection{Antibacterial activities of $A$. calamus and $F$. asafetida}

The antibacterial activity of crude extracts i.e. n-Hexane, dichloromethane, ethyl acetate and ethanol of the selected plants. Traditionally $A$. calamus and $F$. asafetida were used to treat bacterial infections. The results from the current study were screened for their microbial activity against four stander bacteria namely Staphylococcus aureus, staphylococcus epidermidis, Bacillus pubtilis and Escherichia coli. The pattern of inhibition varied with the plant's extract, the solvent used for extraction and the organism tested. DMSO was used as negative control and no inhibition was shown by it against all the bacteria (Bacterial growth inhibition= 0mm). Streptomycin, an antibiotic was used as a positive control. Streptomycin was used as standard drug with significant activity values i.e., 34 against Staphylococcus aureus, 36 against Staphylococcus epidermidis, 30 against Bacillus subtilis and 24 against Escherichia coli. Results of the antibacterial activities of the plants extracts are summarized in table 3 .

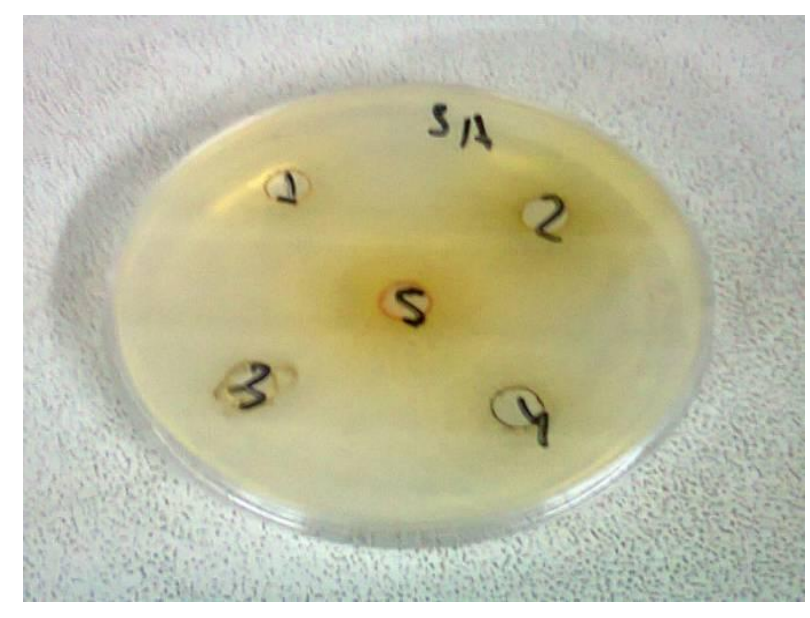

Figure 3. Cup-plate Diffusion Method for ethanolic extracts of the fruits and seeds against Staphylococcus aureus

All the crude extracts, highest antibacterial activities were shown by n-hexane and ethylacetate crude extract of Acorus calamus followed by dichloromethane fraction of Ferula asafetida.. The n-hexane extract of A. calamus showed good activity against Staphylococcus epidermidis and the zone of inhibition seen for it was $16 \mathrm{~mm}$. Non-significant activity of n-hexane extract of $A$. calamus was seen against Escherichia coli and Bacillus subtilis i.e., $12 \mathrm{~mm}$ each, while no activity was shown against Staphylococcus aureus. Non-significant activity was seen for dichloromethane extract against Escherichia coli and Bacillus subtilis i.e., $12 \mathrm{~mm}$ and $10 \mathrm{~mm}$ respectively, while no activity was seen against Staphylococcus aureus and Staphylococcus epidermidis. The ethylacetate of A. calamus showed low activity against Staphylococcus epidermidis with zone of inhibition $14 \mathrm{~mm}$, non significant against Bacillus subtilis (12mm) and Staphylococcus aureus (10mm), while no activity was seen against Escherchia coli. A. calamus, ethanolic extract showed no activity against Bacillus subtilis, Staphylococcus aureus and Escherichia coli, while non significant against Staphylococcus epidermidis (10mm).

The dichloromethane extract of Ferula asafetida was found low against Escherichia coli and Bacillus subtilis i.e., $16 \mathrm{~mm}$ and $14 \mathrm{~mm}$ respectively. While exhibited non-significant activity against Staphylococcus epidermidis (12mm) and no activity against Staphylococcus aureus. The n-Hexane extract of $F$. asafetida showed no activity against Staphylococcus epidermidis and Escherichia coli while nonsignificant against Staphylococcus aureus (12mm) and Bacillus subtilis (10mm). The ethylacetate extract was found non-significant against Bacillus subtilis (12mm), Staphylococcus aureus (12mm) and Escherichia coli (10mm), while no activity was seen against Staphylococcus epidermidis. F. asafetida ethanolic extract showed non-significant activity against Staphylococcus epidermidis $(12 \mathrm{~mm})$ and Escherichia coli (12mm) and Bacillus subtilis (10mm) while no activity was seen against and Staphylococcus. 


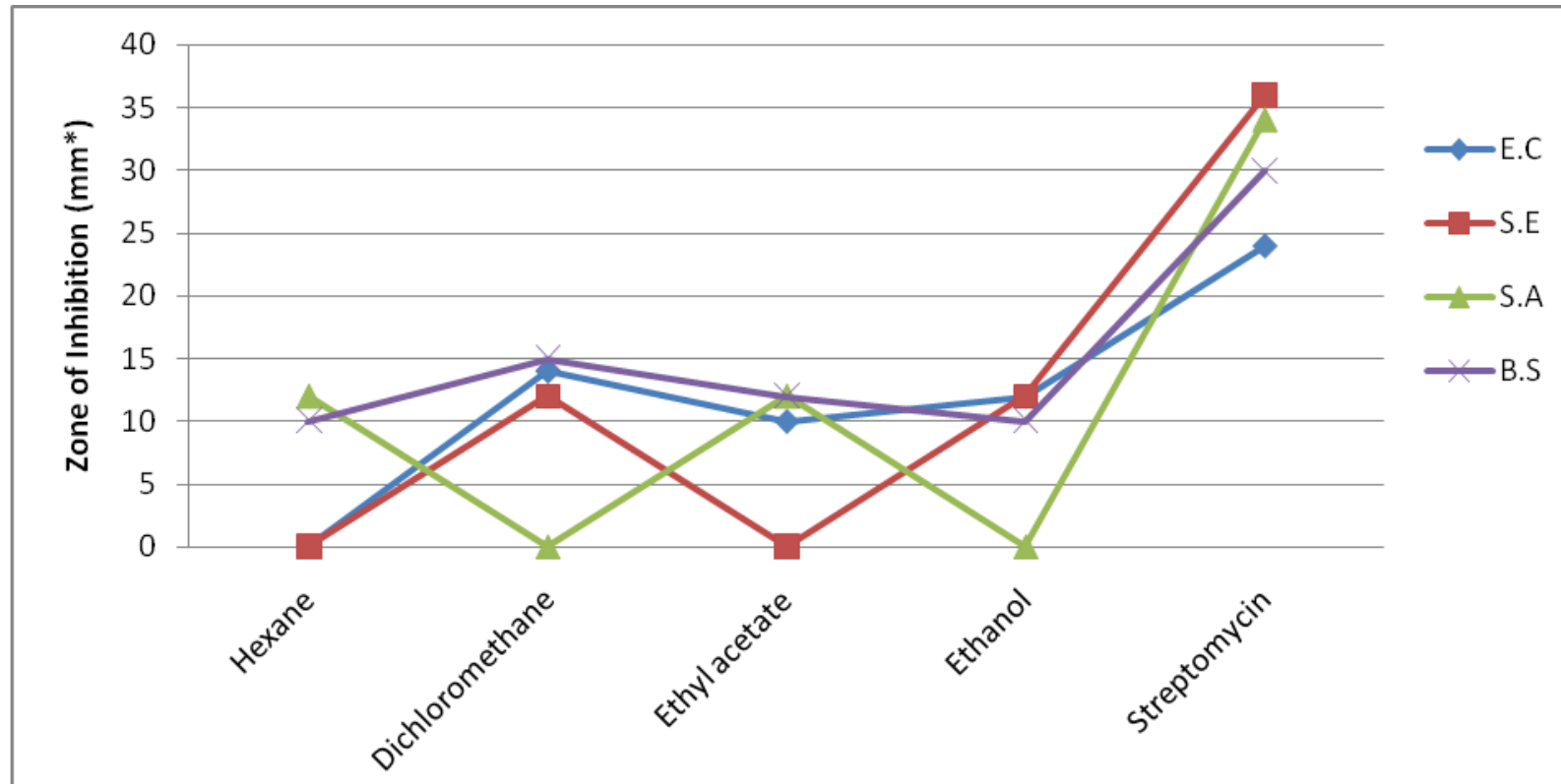

Figure 1. Antibacterial activities of Acorus calamus in differnet solvents

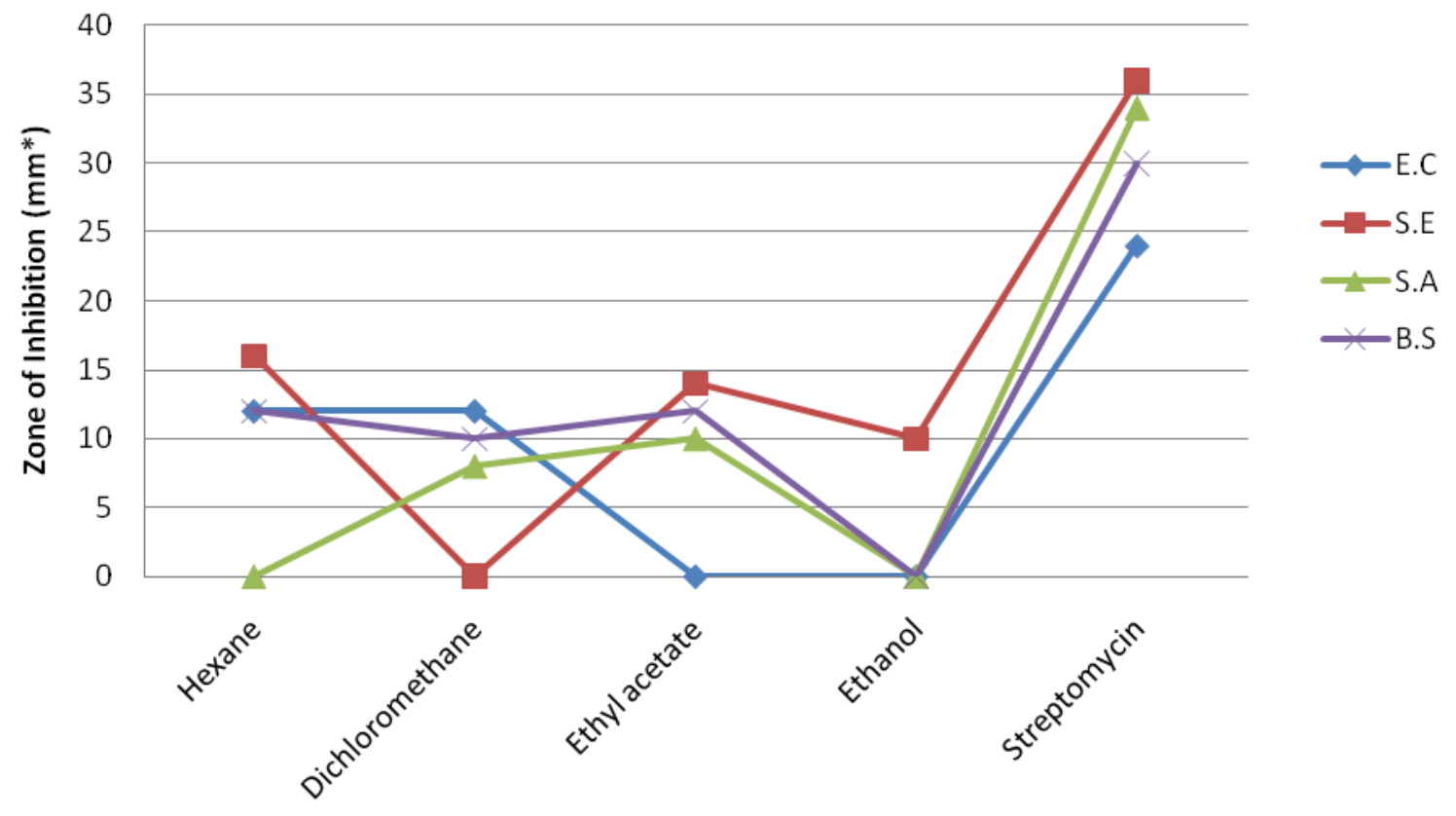

Figure 2. Antibacterial activities of Ferula assafoetida in different solvents 


\section{Discussion}

In the present study the n-Hexane extract of A. calamus $(2 \mathrm{mg} / \mathrm{mL})$ showed that it is potent against bacterial strains as compared to its other extracts illustrate in figure 1. The zone of inhibition shown by it was $16 \mathrm{~mm}$ against Staphylococcus epidermidis. So this plant can be further processed for isolation of active components, inhibiting the growth of this pathogen which may lead to the discovery of potent antibiotic. The potency of the other extracts of A. calamus against bacterial strains was not good enough. This showed that the active components of $A$. calamus are more soluble in $\mathrm{n}$ hexane. The presence of saponins in A. calamus, shown by its dichloromethane and ethanolic extract is the cause of hyperlipdemia in rats, while diarrhea does not occur with large dose of the extract with ethanol. Alcoholic extract is responsible for anti-inflammatory effect while nhexane for spasmolytic effect of the plant. The presence of flavonoids in dichloromethane extract is responsible for showing antibacterial activity particularly against Staphylococcus aureus. Ethylacetate extract showed $14 \mathrm{~mm}$ zone of inhibition against staphylococcus epidermidis whose phytochemical screening showed presence of alkaloids, tannins and terpenoids. This showed that out of these three constituents one, two or all are responsible for its antibacterial activity.

The Dichloromethane extract of Ferula asafetida was found Significant against Escherichia coli and Bacillus subtilis and its zone of inhibition were $(12 \mathrm{~mm})$ and $(10 \mathrm{~mm})$ respectively. The other extracts. F. asafetida contains much of its active components in dichloromethane showed in figure 2. The saponins were the most active constituent in $F$. asafetida because its presence is shown by phytochemical screening of dichloromethane extract. Beside saponins alkaloids and terpenoids were also active against bacterial strains. This plant has many other medicinal properties and thus can be used effectively against other ailments without disturbing the internal normal flora of human.

\section{Conclusion}

The antimicrobial effects of A. calamus and $F$. asafetida extracts against the studied bacteria suggest that, different parts of $A$. calamus and $F$. asafetida possess remarkable therapeutic action that can support the traditional usage of this plant in the treatment of bacterial diseases such as gastrointestinal infection, diarrhea, respiratory and skin diseases. These antimicrobial activities are likely due to the presence of secondary metabolites like tannins and flavonoids, alkaloids, saponins, terpenes and Glycosides in A. calamus and $F$. asafetida. The high potency of $A$. calamus and $F$. asafetida against these microbes could provide an example of prospecting for new compounds.

\section{Acknowledgment}

All the studies were funded by Higher Education Commission of Pakistan, through Indigenous 5000 Fellowship Program.

\section{Conflict of Interest}

The authors have declared that there is no conflict of interest

\section{References}

1. Abdel-Wahab, S.I., Abdul, A.B., Zhew, K., Fong, S.M. Antimicrobial and Free Radical Scavenging Activities of the Dichloromethane Extract of Goniothalamus umbrosus. Intl. J. Trop. Med. 2009, 4: 32-36.

2. Brown. E., Charlotte., Medicinal and Other Uses of North American Plants, A Historical Survey with Special Reference to the Eastern Indian Tribes Dover Publications 1989, 23132.

3. Balakumbahan, R., Rajamani. K., Kumanan. K., Acorus calamus an overview, J. Med. Plant. Res. 2010. 4, 2740 - 2745.

4. Devi, S.A., Ganjewala, D., Antioxidant Activities of Methanolic Extracts of SweetFlag (Acorus calamus) Leaves and Rhizomes. J. Herb. Sp \& Med Plant. 2011, 
17, $1-11 . \quad$ DOI: 10.1080/10496475.2010.509659

5. Syed, F., Jahan, R., Ahmad, A., Khan, S., In vitro antimicrobial activities of Glycyrrhiza glabra and Fagonia Arabica. J. Med. Plant. Res. 2013, 7(10), 2265-2270. DOI:10.5897/JMPR12.629

6. Ghosh, S., In vitro and in vivo efficacy of Acorus calamus extract against Rhipicephalus (Boophilus). Mic. Para. Res. 2011, 108, 361-370. DOI: 10.1007/s00436010-2070-0

7. Johnson, D., Kershaw, K.., Kinnon, AM., Pojar, J., Plants of the Western Boreal Forest \& Aspen Parkland, Edmonton, Canada. 1995.

8. Khan, S. Concept of Natural Product Chemistry, Lambert Academic Publishing, Saarbrücken, Germany, 2012.

9. Lee, M.H., Inhibitory effect of $\beta$-asarone, a component of Acorus calamus essential oil, on inhibition of adipogenesis in 3T3-L1 cells. F. Chem. 2011, 126, 1-7. DOI: 10.1016/j.foodchem.2010.08.052

10. Marcy, J., Balunas, A.A., Douglas, K.B., Drug discovery from medicinal plants. Life Sci. 2005, 78, 431-41. DOI: $\underline{10.1016 / j . l f s .2005 .09 .012}$
11. Meena, A.K., Rao, MM. Singh, A., Kumari, S., Phytochemical and preliminary phytochemical studies on the rhizome of Acorus calamus Linn. Int. J. Pharm and Pharm. Sci. 2010, 2 (2), 130-131.

12. Morningstar. A., Desai, U. The Ayurvedic Cookbook, Lotus Press, Twin Lakes, U.S.A, 1991.

13. Pearson, D., The chemical analysis of foods, Longman Group Limited, New York, U.S.A. 1976.

http://books.google.com.hk/books/about/The chemical_analysis_of_foods.html?id=fqsv AAAAYAAJ

14. Shukla, P.K., Khanna, V.K., Ali, M.M., Maurya, R., Khan, M.Y., Srimal, R.C., Neuroprotective effect of Acorus calamus against middle cerebral artery occlusioninduced ischaemia in rat. Hum. Exp Toxi. $2006, \quad 25, \quad 187-194 . \quad$ DOI: 10.1191/0960327106ht613oa

15. Wichtl, Max., A Hand book of practice on a scientific basis Herbal drugs and phytopharmaceuticals,medpahrm, scientific publisher, Birkenwaldstrasse, Germany, 2004. 